Research Article

\title{
Mechanical and Thermal Properties of UHPC Exposed to High-Temperature Thermal Cycling
}

\author{
In-Hwan Yang $(\mathbb{D}$ ) and Jihun Park \\ Kunsan National University, Department of Civil Engineering, Kunsan, Jeonbuk 54150, Republic of Korea \\ Correspondence should be addressed to In-Hwan Yang; ihyang@kunsan.ac.kr
}

Received 1 July 2019; Revised 30 September 2019; Accepted 23 October 2019; Published 11 November 2019

Academic Editor: Peter Majewski

Copyright (C) 2019 In-Hwan Yang and Jihun Park. This is an open access article distributed under the Creative Commons Attribution License, which permits unrestricted use, distribution, and reproduction in any medium, provided the original work is properly cited.

\begin{abstract}
The effects of high-temperature thermal cycling (temperatures up to $500^{\circ} \mathrm{C}$ ) and steel fiber contents on the mechanical and thermal properties of ultrahigh-performance concrete (UHPC) containing polypropylene (PP) fibers were investigated in this study. The different maximum temperatures for thermal cycling included 300,400 , and $500^{\circ} \mathrm{C}$. The mechanical properties, including the compressive strength and tensile strength, and thermal properties, including the unit weight and thermal conductivity, of the UHPC specimens were measured. The experimental results indicated that the compressive strength, tensile strength, unit weight, and thermal conductivity decreased as the temperature increased to $500^{\circ} \mathrm{C}$. Test results showed that for each maximum temperature, the reduction of the thermal conductivities from one to six thermal cycles was not significant. The thermal conductivity of the UHPC decreased as the unit weight of the UHPC decreased, and the thermal conductivity also decreased as the compressive strength of the UHPC decreased. Scanning electron microscopy (SEM) analysis showed that the microstructures of the UHPC specimens exposed to high temperatures contained voids due to the PP fiber melting. The porosity of the UHPC specimens increased as the maximum temperature of the thermal cycles increased, which decreased the unit weights and thermal conductivities of the UHPC specimens. Moreover, the porosity at a temperature of $500^{\circ} \mathrm{C}$ increased by $60.0,74.5$, and $123.4 \%$ for steel fiber contents of 1.0, 1.5, and 2.0\%, respectively. It might be due to incompatible thermal expansion between the concrete matrix and steel fiber.
\end{abstract}

\section{Introduction}

Burning fossil fuels in power plants could have adverse effects on the environment and therefore bring attention to increasing the use of new and renewable energy sources, such as solar, wind, and geothermal energy. Among these new and renewable energy sources, solar thermal energy is a particularly useful energy source [1-3].

For an economical and efficient supply of solar thermal energy, a thermal energy storage system is indispensable because it is important to maintain constant solar energy during the night and in adverse weather conditions, such as cloudy weather. The energy stored in the energy storage system can be used during times of adverse weather conditions and at night to supply constant electricity $[4,5]$. In conventional storage methods where the temperature exceeds $100^{\circ} \mathrm{C}$, pressure vessels have been used to pressurize steam. However, this method is not economical because of the high cost required to design and build pressure vessels. Laing et al. [5] and John et al. [6] suggested an alternative method that uses solid media for sensible heat storage. In sensible heat storage, thermal energy is stored in a solid or liquid medium by elevating the temperature of the medium. Previous study results $[7,8]$ show that in terms of low energy production cost and wide material applications, concrete is a more promising solid medium for thermal energy storage than other candidate solid media, such as cast irons, aluminum alloys, and graphite.

The German Aerospace Center integrated a concrete thermal energy storage system into a parabolic trough test loop in a concentrating solar power plant in Spain in 2003 $[9,10]$. To develop an efficient concrete solid media for thermal energy storage, extensive investigations on the mechanical and thermal properties of concrete are required. 
Yuan et al. [11] studied the influences of various amounts of nano- $\mathrm{ZrO}_{2}$ on the performance, such as compressive strength, thermal conductivity, and thermal expansion coefficient, of cementitious composites. In addition, Yuan et al. [12] investigated the compressive strength and thermal conductivity of high-temperature aluminate cementitious materials, including nano- $\mathrm{MgO}$, for thermal energy storage. Their test results showed that the addition of $\mathrm{MgO}$ in cementitious materials enhanced the thermal conductivity of concrete.

Ultrahigh-performance concrete (UHPC) is an advanced composite material reinforced with steel fibers that exhibits higher compressive strength and tensile strength than conventional concrete [13-17]. Moreover, the high tensile strength of UHPC provides a high resistance to thermal cracking. However, studies on the mechanical and thermal properties of UHPC specimens exposed to high-temperature thermal cycles are still limited, whereas some investigations on the deterioration of UHPC and reactive powder concrete (RPC) specimens under a single thermal exposure to fire have been performed [18-20]. Therefore, to apply UHPC as a solid media for thermal energy storage, studies must be performed on the mechanical and thermal properties of UHPC specimens under high-temperature thermal cycles.

In this study, the mechanical and thermal properties of UHPC specimens containing steel fiber contents of 1.0, 1.5, and $2.0 \%$ were exposed to high-temperature thermal cycles ranging from 300 to $500^{\circ} \mathrm{C}$. The compressive strengths, tensile strengths, unit weights, and thermal conductivities were measured before and after the UHPC specimens were exposed to thermal cycling. The relationships between the thermal conductivity and unit weight and between the thermal conductivity and compressive strength of the UHPC were also examined. In addition, scanning electron microscopy (SEM) and mercury intrusion porosimetry (MIP) analyses were performed to characterize the microstructures and pore distributions of the UHPC specimens.

\section{Mixing Proportions of UHPC}

The UHPC mixtures used in this study included straight steel fibers at volume fractions of 1.0, 1.5, and 2.0\%. Ordinary Portland cement (OPC) was used as the cementitious material, and fine aggregates with diameters of $0.5 \mathrm{~mm}$ or less were used. Fine aggregate used in this study was the quartz sand. The $\mathrm{SiO}_{2}$ content in quartz was more than $95 \%$. The water-binder ratio (w/b) was 0.22 , and a polycarboxylic acidbased high-performance water-reducing agent with a density of 1.01 was used to ensure the workability of these mixtures at this low water-binder ratio. In addition, filler, zirconium, and blast furnace slag were also used in the UHPC mixtures.

Three UHPC mixtures, UHPC-F10, UHPC-F15, and UHPC-F20, were fabricated, where the number in each mixture label represents the steel fiber content in the concrete. A type of straight steel fiber with a length of $19.5 \mathrm{~mm}$ was used in the mixtures, as shown in Figure 1(a). The straight steel fibers each had a diameter of $0.2 \mathrm{~mm}$, a unit weight of $7500 \mathrm{~kg} / \mathrm{m}^{3}$, and a tensile strength of $2500 \mathrm{MPa}$.
The detailed mixing proportions of each mixture are shown in Table 1.

A review of the literature [21-25] showed that concrete creates a high internal vapor pressure when exposed to elevated temperatures, which may result in explosive spalling of concrete. At room temperature, polypropylene (PP) fibers enhance the tension resistance of concrete and prevent cracks. PP fibers also prevent spalling caused mainly by the accumulation of the internal pore pressures and thermal stresses in concrete. Accordingly, all mixtures of UHPC used in this study contained PP fibers with a unit weight of $2 \mathrm{~kg} /$ $\mathrm{m}^{3}$ to avoid concrete spalling. A type of monofilament PP fiber with a specific weight of 0.91 and a melting point of $160^{\circ} \mathrm{C}$ was used, as shown in Figure 1(b). The PP fibers were straight fibers that each had a diameter of $21 \mu \mathrm{m}$ and a length of $12 \mathrm{~mm}$.

\section{Experimental Program}

3.1. Specimen Preparation and Test Methods. Cylindrical specimens with diameters of $100 \mathrm{~mm}$ and heights of $200 \mathrm{~mm}$ were fabricated from each mixture. The specimens were covered with plastic wrap and moist-cured for the first day after casting. Then, the specimens were demolded and steam-cured at $90 \pm 5^{\circ} \mathrm{C}$ for 72 hours. After the specimens were steam-cured, the specimens were moist-cured until 28 days after specimen fabrication. Finally, the specimens were cured at $24^{\circ} \mathrm{C}$ for a minimum of 24 hours before testing.

The experiments for compressive strength, tensile strength, unit weight, ultrasonic velocity, and thermal conductivity were performed. Each experiment was performed before and after the specimens were exposed to elevated temperatures in 6 thermal cycles.

3.2. Thermal Cycling Procedure. For thermal storage with the concept of sensible heat of solid media, the thermal storage contains a pipe heat exchanger to transfer the thermal energy to or from the heat transfer fluid [1]. In typical parabolic trough power plants, thermal fluid from the thermal collectors enters the storage with temperatures ranging from 300 to $390^{\circ} \mathrm{C}[1,9]$. Therefore, concrete specimens in this study were heated under the heating scenarios with three different maximum temperatures of 300,400 , and $500^{\circ} \mathrm{C}$, as shown in Figure 2.

The specimen heating began at ambient temperature, and the specimens were heated to the maximum temperature, 300,400 , or $500^{\circ} \mathrm{C}$, for two hours in the furnace, shown in Figure 3. The temperature remained at the maximum temperature for two hours and then returned to the ambient temperature. This thermal cycle was repeated 6 times. For each mixture, a thermocouple was installed at the core of the specimen for temperature measurements. Typical measurements of the actual temperatures at the core of a concrete specimen and furnace are shown in Figure 4, where the solid and dotted lines represent the furnace temperature profile and the concrete core temperature, respectively.

After cooling the specimens in each cycle, the specimens were removed from the furnace, and the unit weight, 


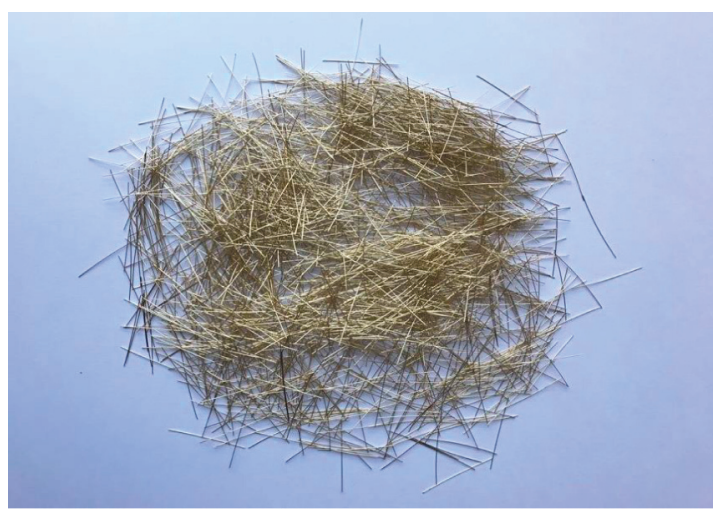

(a)

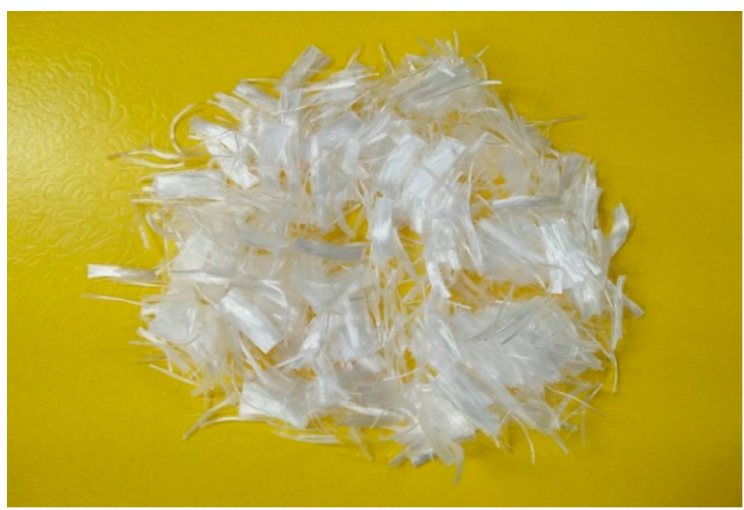

(b)

FIGURE 1: (a) Steel fibers and (b) polypropylene fibers used for the UHPC.

TABLE 1: Mixing proportion of the UHPC.

\begin{tabular}{|c|c|c|c|c|c|c|c|c|c|}
\hline \multirow[b]{2}{*}{ Mixture } & \multirow[b]{2}{*}{$\mathrm{W} / \mathrm{B}$} & \multirow[b]{2}{*}{$\mathrm{W}\left(\mathrm{kg} / \mathrm{m}^{3}\right)$} & \multicolumn{3}{|c|}{$\begin{array}{l}\text { Binders } \\
\left(\mathrm{kg} / \mathrm{m}^{3}\right)\end{array}$} & \multirow{2}{*}{$\begin{array}{c}\mathrm{S} \\
\left(\mathrm{kg} / \mathrm{m}^{3}\right)\end{array}$} & \multirow{2}{*}{$\begin{array}{c}\mathrm{F} \\
\left(\mathrm{kg} / \mathrm{m}^{3}\right)\end{array}$} & \multicolumn{2}{|c|}{ Fibers } \\
\hline & & & OPC & $\mathrm{Zr}$ & BFS & & & $\begin{array}{l}\text { Steel fiber content by volume of } \\
\text { concrete }(\%)\end{array}$ & $\begin{array}{l}\text { PP fiber content by mass } \\
\left(\mathrm{kg} / \mathrm{m}^{3}\right)\end{array}$ \\
\hline UHPC-F10 & 0.22 & 209 & 770 & 58 & 135 & 847 & 231 & 1.0 & 2.0 \\
\hline UHPC-F15 & 0.22 & 209 & 770 & 58 & 135 & 847 & 231 & 1.5 & 2.0 \\
\hline UHPC-F20 & 0.22 & 209 & 770 & 58 & 135 & 847 & 231 & 2.0 & 2.0 \\
\hline
\end{tabular}

W: water, OPC: ordinary Portland cement, Zr: zirconium, BFS: blast furnace slag, S: sand, and F: filler.

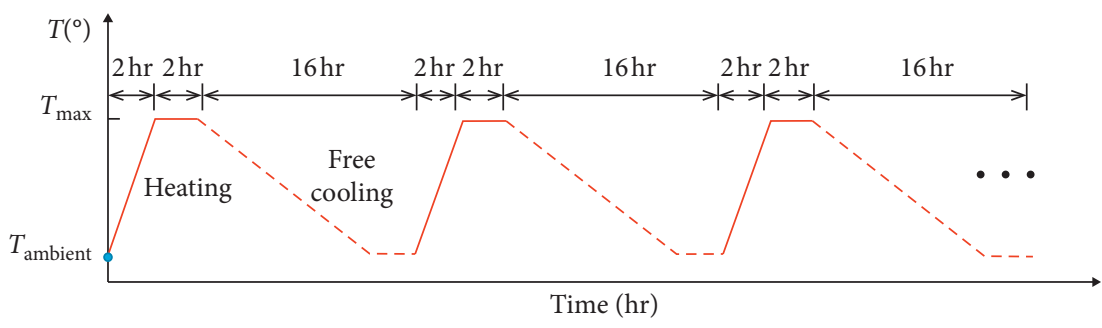

FIgURE 2: Thermal cycling process.

ultrasonic velocity, and thermal conductivity of each specimen were measured. Then, the specimens were returned to the furnace. However, the compressive and tensile strengths of the concrete specimens were measured only after the final cycle because there was not enough space in the furnace to hold the specimens to measure the compressive and tensile strengths after every thermal cycle.

\section{Test Results and Discussion}

4.1. Compressive Strength. The compressive strength of UHPC was measured with the cylindrical specimens using hydraulic machinery with a maximum capacity of $2000 \mathrm{kN}$. The compressive strength test was performed before and after the specimens were exposed to the six high-temperature thermal cycles.

Figure 5(a) shows the effects of different maximum temperatures on the residual compressive strengths of the
UHPC specimens before and after the concrete specimens were exposed to six thermal cycles with different maximum temperatures. At the initial state with an ambient temperature of $25^{\circ} \mathrm{C}$, the compressive strengths of the F10, F15, and F20 series mixtures were $122.8,138.7$, and $145.3 \mathrm{MPa}$, respectively. When the specimens were exposed to thermal cycling at a maximum temperature of $300^{\circ} \mathrm{C}$, the compressive strengths of the F10, F15, and F20 series mixtures slightly decreased by $4.8,3.6$, and $4.2 \%$, respectively. Similarly, after thermal cycling at a maximum temperature of $400^{\circ} \mathrm{C}$, the compressive strengths of the F10, F15, and F20 series mixtures decreased by $9.6,8.8$, and $8.2 \%$, respectively. However, when the specimens were exposed to thermal cycling at a maximum temperature of $500^{\circ} \mathrm{C}$, the compressive strengths of the F10, F15, and F20 series mixtures decreased more substantially by $25.4,16.4$, and $19.0 \%$, respectively. The test results showed that compared with the maximum temperatures of 300 and $400^{\circ} \mathrm{C}$, the decrease in 


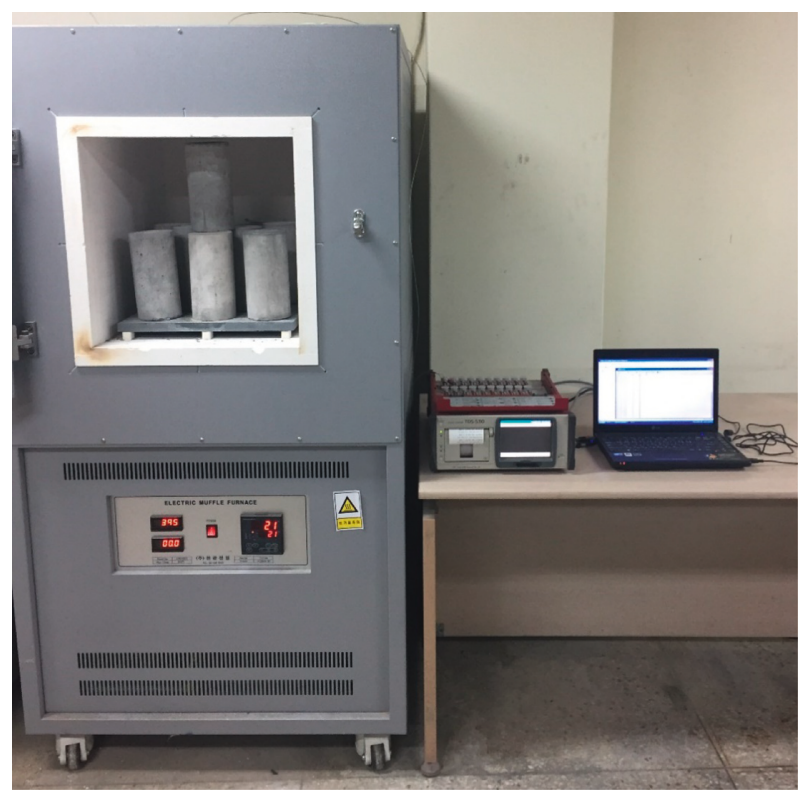

FIgURE 3: Test setup of the UHPC specimens in the furnace.

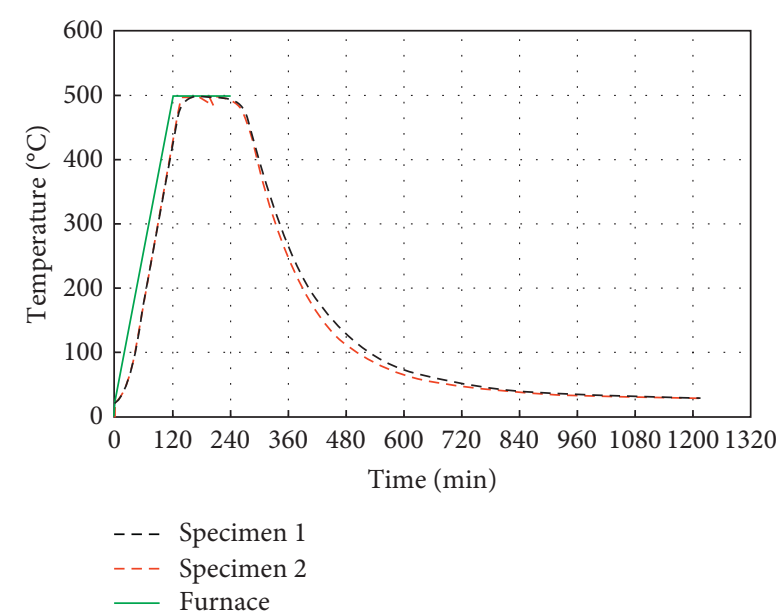

FIgURE 4: Typical measurement of the temperatures at the cores of the concrete specimens.

the residual compressive strength at a maximum temperature of $500^{\circ} \mathrm{C}$ was remarkable. A considerable decrease in the compressive strength at $500^{\circ} \mathrm{C}$ occurs because most of bound water in the cement paste is lost when the concrete is subjected to high temperatures between 400 and $500^{\circ} \mathrm{C}$, and calcium hydroxide in the cement paste begins to dehydrate between approximately $500^{\circ} \mathrm{C}$ and $600^{\circ} \mathrm{C}[23]$.

The compressive strengths of the concrete specimens with different steel fiber contents are shown in Figure 5(b). The compressive strengths of the concrete specimens gradually increased as the steel fiber content increased from $1.0 \%$ to $2.0 \%$ at the initial state with an ambient temperature of $25^{\circ} \mathrm{C}$. For the specimens exposed to maximum temperatures of 300 and $400^{\circ} \mathrm{C}$, the compressive strengths of the concrete specimens gradually increased as the steel fiber content increased from $1.0 \%$ to $2.0 \%$. However, for the specimens exposed to a maximum temperature of $500^{\circ} \mathrm{C}$, the compressive strength increase was not substantial as the steel fiber content increased from $1.5 \%$ to $2.0 \%$.

4.2. Splitting Tensile Strength. To measure the tensile strength of UHPC, splitting tensile strength tests were performed using cylindrical specimens. The tensile strength tests were performed before and after the specimens were exposed to the six high-temperature thermal cycles.

The tensile strengths of the UHPC specimens before and after exposure to the six thermal cycles with different maximum temperatures are shown in Figure 6(a). The trend of the tensile test results was similar to that of the compressive test results. The tensile strength gradually decreased as the maximum temperature increased to $400^{\circ} \mathrm{C}$. However, compared with the maximum temperatures of 300 and $400^{\circ} \mathrm{C}$, the tensile strength decreased more substantially when the concrete was exposed to a maximum temperature of $500^{\circ} \mathrm{C}$. The decrease in tensile strength at a maximum temperature of $500^{\circ} \mathrm{C}$ conformed to that of compressive strength at a maximum temperature of $500^{\circ} \mathrm{C}$.

The tensile strengths of the concrete specimens with different steel fiber contents are also shown in Figure 6(b). The test results show that the steel fiber content substantially contributed to the tensile strength of the UHPC. When the steel fiber content increased from $1.0 \%$ to $1.5 \%$, the tensile strengths of the concrete specimens at the initial state of $25^{\circ} \mathrm{C}$ and the maximum temperatures of 300,400 , and $500^{\circ} \mathrm{C}$ increased by $19.4,20.9,20.4$, and $33.8 \%$, respectively. Additionally, when the steel fiber content increased from $1.0 \%$ to $2.0 \%$, the tensile strengths of the concrete specimens at the initial state of $25^{\circ} \mathrm{C}$ and the maximum temperatures of 300 , 400 , and $500^{\circ} \mathrm{C}$ increased by $26.5,27.3,28.5$, and $37.4 \%$, respectively.

\subsection{Unit Weight}

4.3.1. Effects of Thermal Cycling on the Unit Weight. The amount of energy stored in an energy storage medium depends on the unit weight of the medium. Therefore, the unit weight of the concrete is an important factor in storing energy in a given volume of concrete. In addition, to accurately simulate the thermodynamics of thermal energy storage, information regarding the unit weight of concrete is required. In this study, the unit weight of each mixture was measured before and after every thermal cycle.

The unit weights of the specimens before and after the thermal cycles with different maximum temperatures are shown in Figure 7 . The unit weight decreased immediately after the first thermal cycle, but there was little change in the unit weight of the concrete after the second cycle. This implies that the concrete almost reached physical stability after the second thermal cycle.

4.3.2. Effects of the Maximum Temperature and Steel Fiber Content on the Unit Weight. A comparison of the unit weights of the mixtures before and after six thermal cycles is 


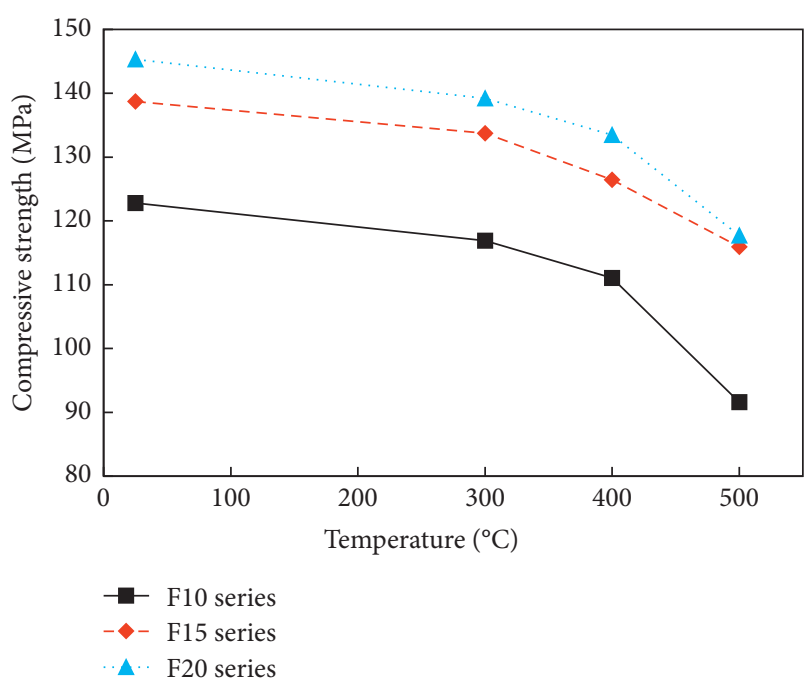

(a)

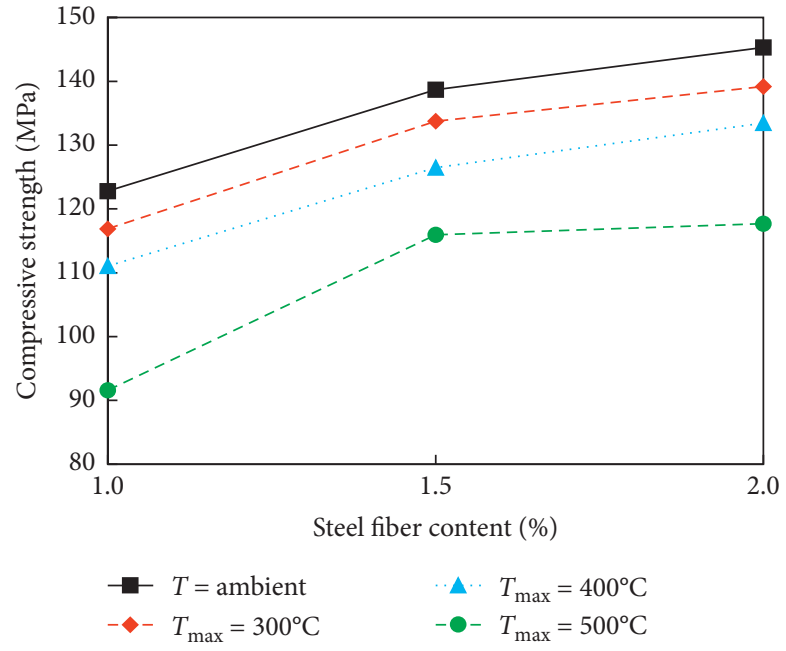

(b)

FIGURE 5: Compressive strength test results. (a) Relationship between the compressive strength and the maximum temperature. (b) Relationship between the compressive strength and the steel fiber content.

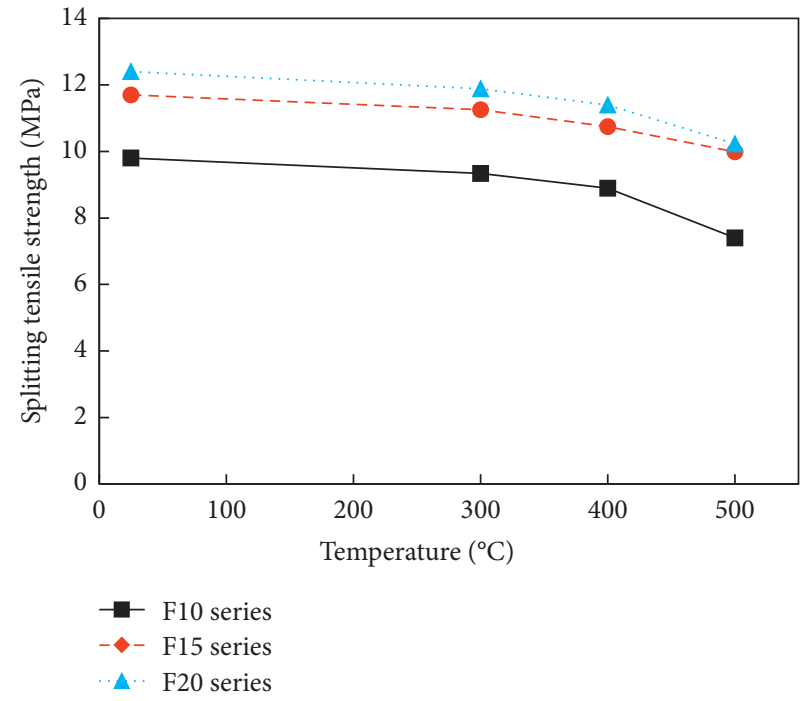

(a)

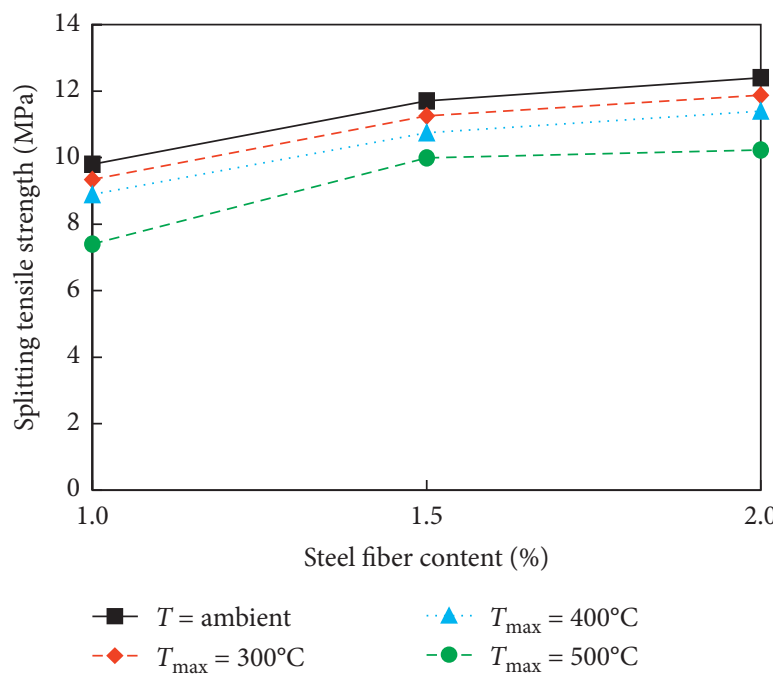

(b)

FIGURE 6: Splitting tensile strength test results. (a) Relationship between the tensile strength and the maximum temperature. (b) Relationship between tensile strength and steel fiber content.

shown in Figure 8. The unit weight decreased substantially after exposure to a maximum temperature of $300^{\circ} \mathrm{C}$, and the unit weight gradually decreased as the maximum temperature increased.

When the UHPC contained a steel fiber content of 1.0\%, the reduction in the unit weight after six thermal cycles was $7.0,7.2$, and $7.7 \%$ for the maximum temperatures of 300 , 400 , and $500^{\circ} \mathrm{C}$, respectively. Additionally, the unit weights of the specimens with steel fiber contents of $2.0 \%$ decreased by $6.6,7.3$, and $8.0 \%$ after six thermal cycles at maximum temperatures of 300,400 , and $500^{\circ} \mathrm{C}$, respectively. The loss in the unit weight in the case of the maximum temperature of $500^{\circ} \mathrm{C}$ was greater than that at maximum temperatures of
300 and $400^{\circ} \mathrm{C}$. This phenomenon may be attributed to the dehydration of the UHPC, which was greater after thermal cycling at a maximum temperature of $500^{\circ} \mathrm{C}$ than after thermal cycling at maximum temperatures of 300 and $400^{\circ} \mathrm{C}$.

Figure 8 also shows that the unit weight at the same temperature condition increased as the steel fiber content increased. The steel fibers are added to improve the tensile strength and toughness of the UHPC [13]. In addition to improving these characteristics, the addition of steel fibers in the UHPC increases the unit weight, which is advantageous for storing high amounts of thermal energy. However, the unit weight difference of two different mixtures at each elevated temperature was not substantial, which meant that 


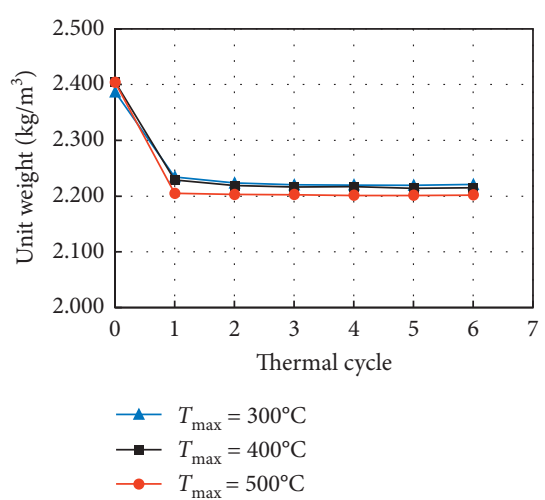

(a)

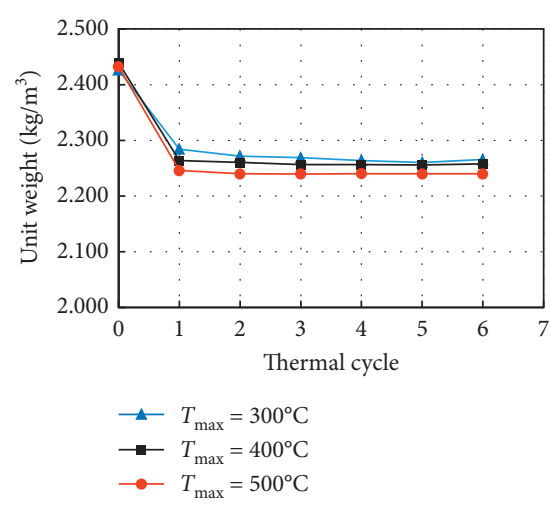

(b)

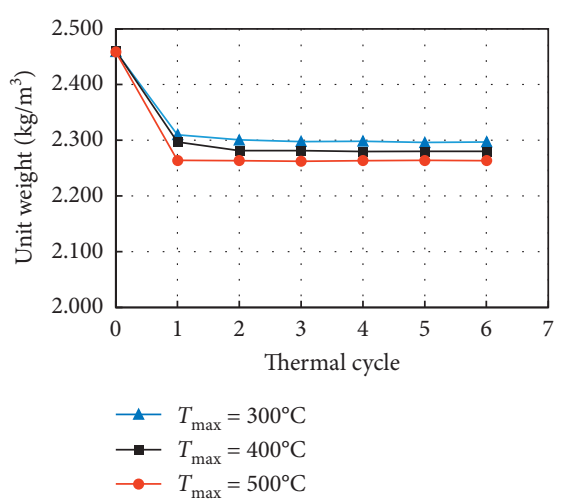

(c)

Figure 7: Variations in unit weight during thermal cycling at different maximum temperatures. (a) Steel fiber content $=1.0 \%$. (b) Steel fiber content $=1.5 \%$. (c) Steel fiber content $=2.0 \%$.

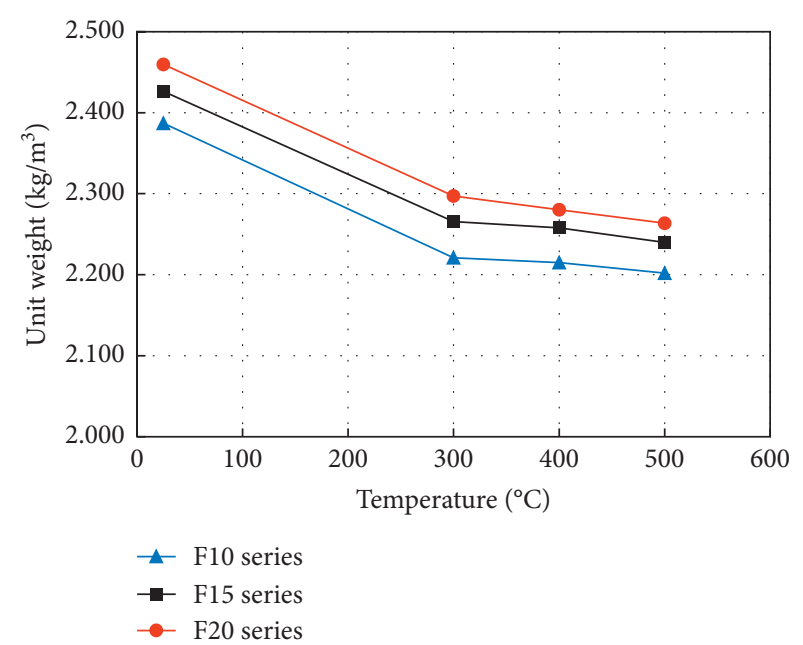

FIGURE 8: Comparison of unit weights before and after six thermal cycles.

steel fiber contents hardly affected the reduction in the unit weight of the UHPC at various high temperatures.

A comparison of the unit weights of the mixtures after one and six thermal cycles is shown in Figure 9. The slope of the unit weights from ambient temperature up to $300^{\circ} \mathrm{C}$ was steep, which resulted from the evaporation of free water and bound water [20]. When the UHPC contained a steel fiber content of $1.0 \%$, the reduction in the unit weight from one up to six thermal cycles was $0.6,0.6$, and $0.1 \%$ for the maximum temperatures of 300,400 , and $500^{\circ} \mathrm{C}$, respectively. In addition, the unit weights of the specimens with steel fiber contents of $1.5 \%$ decreased by $0.8,0.3$, and $0.3 \%$ from one to six thermal cycles at maximum temperatures of 300,400 , and $500^{\circ} \mathrm{C}$, respectively. Test results showed that reduction of the unit weight of the mixtures at each maximum temperature was not significant. It means that most of free water and bound water were evaporated during the first thermal cycle, and so there was little difference between the unit weights after one and six thermal cycles.

\subsection{Thermal Conductivity}

4.4.1. Effects of Thermal Cycling on the Thermal Conductivity. The thermal conductivity of each specimen was measured before and after every thermal cycle. A transient plane source (TPS) measurement system was used to evaluate the thermal conductivity. The TPS measurement method was described in detail by Log and Gustafsson [26], and the extensive applications of the TPS measurement method were summarized by Bentz et al. [27]. The detector was inserted horizontally between the cast sides of the two concrete specimens. After a thermal equilibrium time of at least $90 \mathrm{~min}$ in laboratory temperature conditions, measurements were made with a power of $0.3 \mathrm{~W}$ applied for a measurement time of approximately $90 \mathrm{sec}$. The thermal conductivity was measured at the intervening time separating two continuous thermal cycles.

The thermal conductivities of the mixtures before and after exposure to thermal cycles with different maximum temperatures are shown in Figure 10. The thermal conductivity decreased sharply after the first cycle, but there was little change in the thermal conductivity of the concrete after the second cycle. The variation in the thermal conductivity during thermal cycling is similar to that of the unit weight. This similarity implies that the thermal conductivity characteristics are related to the unit weight characteristics.

4.4.2. Effects of the Maximum Temperature and Steel Fiber Content on the Thermal Conductivity. The thermal conductivities of the mixtures before and after exposure to thermal cycles with different maximum temperatures are shown in Figure 11. When the UHPC specimens were exposed to six thermal cycles at a maximum temperature of $300^{\circ} \mathrm{C}$, the thermal conductivities of the F10, F15, and F20 mixtures decreased by $24.0,23.0$, and $22.8 \%$, respectively. In addition, after six thermal cycles at a maximum temperature of $400^{\circ} \mathrm{C}$, the thermal conductivities of the F10, F15, and F20 mixtures decreased by $29.2,26.2$, and $28.2 \%$, respectively. Moreover, after six thermal cycles at a maximum temperature 


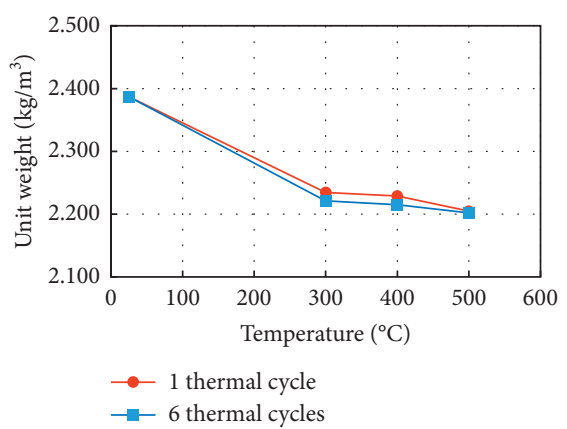

(a)

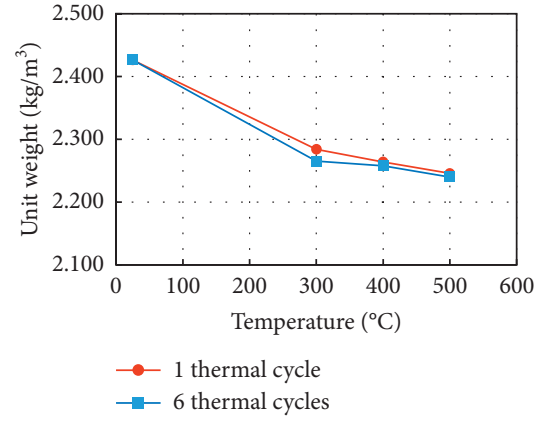

(b)

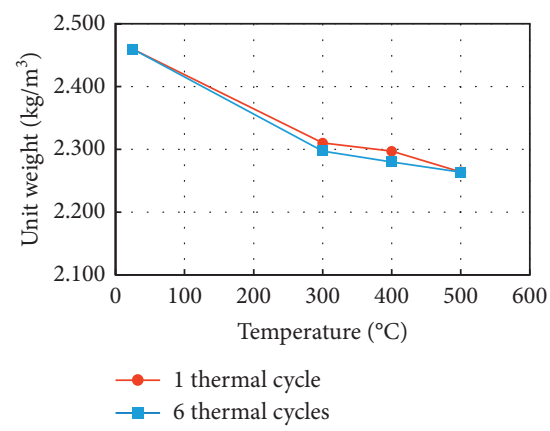

(c)

Figure 9: Comparison of unit weights after one and six thermal cycles. (a) Steel fiber content $=1.0 \%$. (b) Steel fiber content $=1.5 \%$. (c) Steel fiber content $=2.0 \%$.

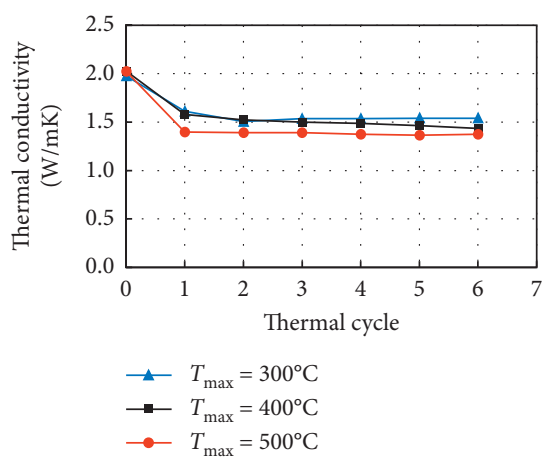

(a)

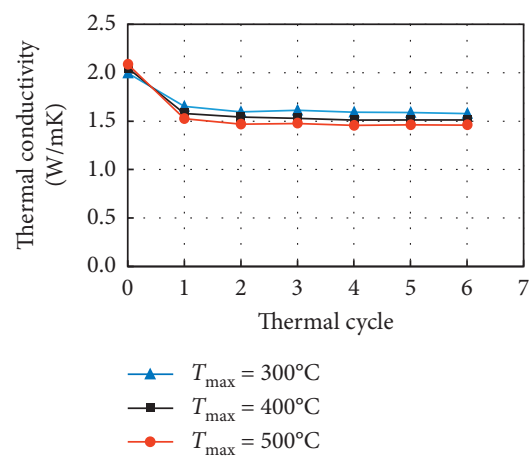

(b)

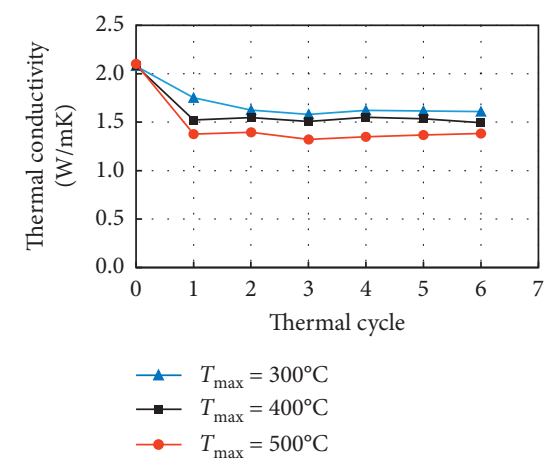

(c)

FIGURE 10: Variations in thermal conductivity during thermal cycling at different maximum temperatures. (a) Steel fiber content $=1.0 \%$. (b) Steel fiber content $=1.5 \%$. (c) Steel fiber content $=2.0 \%$.

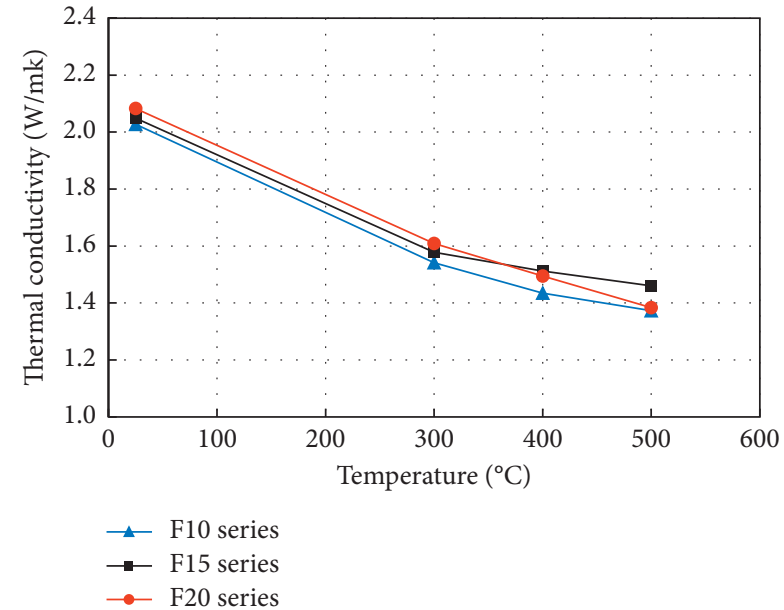

Figure 11: Comparison of thermal conductivities before and after six thermal cycles.

of $500^{\circ} \mathrm{C}$, the thermal conductivities of the F10, F15, and F20 mixtures decreased by $32.3,28.7$, and $33.6 \%$, respectively.

The decreasing rate of the thermal conductivity was most substantial when the maximum temperature of the thermal cycle was $300^{\circ} \mathrm{C}$, and the rate was slightly reduced when the maximum temperature of the thermal cycle was 400 and $500^{\circ} \mathrm{C}$. Free water and bound water in the cement paste begin to evaporate when the temperature reaches $200^{\circ} \mathrm{C}$, and most of bound water evaporates when the temperature approaches $500^{\circ} \mathrm{C}$. In addition, the decomposition of $\mathrm{CH}$ and $\mathrm{C}-\mathrm{S}-\mathrm{H}$ hydrates begins when the temperature ranges from 400 to $500^{\circ} \mathrm{C}$ [20]. The decomposition of $\mathrm{CH}$ and C-S-H hydrates makes the cement matrix more porous. Therefore, the thermal conductivity of the UHPC in this study gradually decreased when the temperature ranges from 300 to $500^{\circ} \mathrm{C}$.

Test result also indicates that for thermal cycling at a maximum temperature of $500^{\circ} \mathrm{C}$, the decrease in thermal conductivity was greater than that of the other thermal cycles at different maximum temperatures. The porosity volume of the concrete increases as the temperature increases, and the connectivity among the solid phases of the matrix in the concrete is lost, which means that a greater number of defects are created in the matrix; this phenomenon decreases the thermal conductivity of the concrete [21, 25].

The decrease rate of $32.3,28.7$, and $33.6 \%$ in thermal conductivities at different steel fiber contents was not consistent. Especially, the decrease rate of the mixture with $1.5 \%$ steel fiber content (F15 series) was the smallest among the three series. This phenomenon might be due to incompatible thermal expansion between the concrete matrix and steel fiber, which could make the interface zone between 
the matrix and steel fiber weak and more porous. Additionally, the uneven dispersion of steel fibers in concrete might cause inconsistent decrease rate in the thermal conductivities.

The effects of the steel fiber content on the thermal conductivity can also be found in Figure 11. As the steel fiber content increased from $1.0 \%$ to $1.5 \%$, the thermal conductivity increased by $1.1 \%$ at the ambient temperature and by $2.4,5.4$, and $6.3 \%$ after the specimens were exposed to thermal cycling at maximum temperatures of 300,400 , and $500^{\circ} \mathrm{C}$, respectively. In addition, as the steel fiber content increased from $1.0 \%$ to $2.0 \%$, the thermal conductivity increased by $2.7 \%$ at ambient temperature and by 4.4, 4.2, and $0.8 \%$ after thermal cycling at maximum temperatures of 300,400 , and $500^{\circ} \mathrm{C}$, respectively. The thermal conductivity of the concrete reinforced by steel fibers increases as the steel fiber content increases because the thermal conductivity of the steel fiber is greater than that of the matrix in the concrete. However, the test results in this study showed that the steel fiber content did not substantially affect the thermal conductivity. This small change in thermal conductivity was because a small amount of steel fiber content less than $2.0 \%$ by volume of concrete was used in this study.

A comparison of the thermal conductivities of the mixtures after one and six thermal cycles is shown in Figure 12. The slope of the thermal conductivities from ambient temperature up to $300^{\circ} \mathrm{C}$ was steep. The reduction in thermal conductivities was also due to the evaporation of free water and bound water, as was the reduction in unit weights. When the UHPC contained a steel fiber content of $1.0 \%$, the reduction in the thermal conductivity from one to six thermal cycles was $4.4,9.2$, and $1.7 \%$ for the maximum temperatures of 300,400 , and $500^{\circ} \mathrm{C}$, respectively. In addition, the thermal conductivities of the specimens with steel fiber contents of $1.5 \%$ decreased by $4.5,4.3$, and $4.2 \%$ from one to six thermal cycles at maximum temperatures of 300,400 , and $500^{\circ} \mathrm{C}$, respectively. It represented that for each maximum temperature, the reduction of the thermal conductivities from one to six thermal cycles was not significant.

4.4.3. Relationship between the Thermal Conductivity and Unit Weight. The relationship between the thermal conductivity and unit weight of the UHPC under different maximum temperatures is shown in Figure 13. There are two remarkable measurement groups in the figure. For the first group, the measurements of the thermal conductivity and unit weight of the UHPC were made at the ambient temperature condition. For the second group, the measurements of the thermal conductivity and unit weight of the UHPC were made after the thermal cycling was completed under the different maximum temperatures of 300,400 , and $500^{\circ} \mathrm{C}$. The unit weight of the UHPC ranged from 2387 to $2461 \mathrm{~kg} /$ $\mathrm{m}^{3}$ and the thermal conductivity ranged from 1.98 to $2.10 \mathrm{~W} / \mathrm{mK}$ at ambient temperature, while the unit weight of the UHPC ranged from 2201 to $2310 \mathrm{~kg} / \mathrm{m}^{3}$ and the thermal conductivity ranged from 1.32 to $1.75 \mathrm{~W} / \mathrm{mK}$ after the hightemperature thermal cycling.
Figure 13 also shows that the overall thermal conductivity of the UHPC decreased as the unit weight of the UHPC decreased. In addition, the thermal conductivity of the UHPC is almost linearly proportional to the unit weight, as shown in Figure 13. This phenomenon occurs because the bound water content in the cement paste begins to decrease when the temperature reaches $200^{\circ} \mathrm{C}$, and most of bound water in the cement paste is eliminated when the temperature reaches $500^{\circ} \mathrm{C}$. Accordingly, the unit weight and thermal conductivity of the UHPC are reduced substantially.

4.4.4. Relation between the Thermal Conductivity and Compressive Strength. The decrease in the compressive strength and thermal conductivity of the UHPC subjected to high-temperature thermal cycling resulted from the decrease in the unit weight of the UHPC. Therefore, the relationship between the thermal conductivity and compressive strength of the UHPC under different thermal cycling conditions is investigated and shown in Figure 14. As expected, the overall thermal conductivity of the UHPC decreased as the compressive strength of the UHPC decreased. Typically, when the UHPC was exposed to thermal cycling at a maximum temperature of $500^{\circ} \mathrm{C}$, the thermal conductivity of the UHPC decreased by $32.1,30.0$, and $34.1 \%$ for steel fiber contents of $1.0,1.5$, and $2.0 \%$, respectively, while the compressive strength of the UHPC decreased by $25.4,16.4$, and $19.0 \%$ for steel fiber contents of 1.0, 1.5, and 2.0\%, respectively.

4.5. Investigation of the Specimen Microstructures. To investigate the microstructure of the UHPC before and after thermal cycling, SEM image analysis was performed. The microstructure of UHPC at an ambient temperature of approximately $25^{\circ} \mathrm{C}$ is shown in Figure 15 (a). As shown in the figure, the existence of the PP fibers was observed in the UHPC matrix. In addition, the microstructures of the UHPC exposed to maximum temperatures of 300,400 , and $500^{\circ} \mathrm{C}$ under thermal cycling are shown in Figures 15(b)-15(d), respectively. These figures show voids from the PP fiber melting.

The PP fibers play an important role in enhancing the mechanical properties of the UHPC. The presence of the PP fibers connects the particles of the cement paste. PP fibers are melted at a temperature of approximately $160^{\circ} \mathrm{C}$ and create some voids in the concrete matrix. This phenomenon results in the reduction in the compressive strength, splitting tensile strength, unit weight, and thermal conductivity of the UHPC, as discussed in the previous sections.

By combining the SEM and MIP experimental results, a more complete understanding of the pore structure of the UHPC is possible. The MIP method has been extensively applied to characterize the porosity structure of cementitious materials for many years. In this study, the MIP method can present views of how different thermal cycles affect the porosity properties of the UHPC specimens.

A comparison of the porosity percentage of UHPC before and after exposure to thermal cycling at different high temperatures is shown in Figure 16. The porosity volume increased as the thermal cycling temperature increased. For 


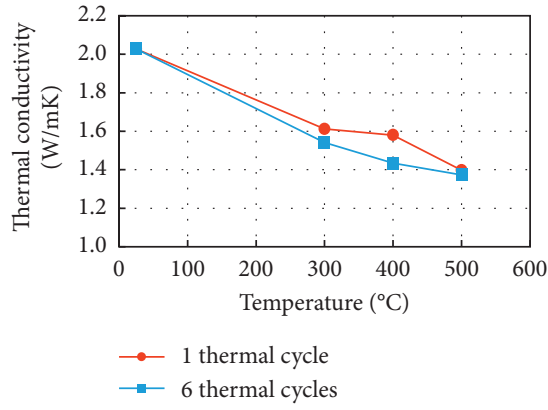

(a)

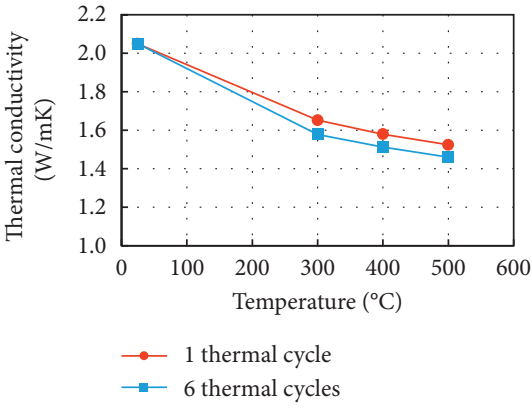

(b)

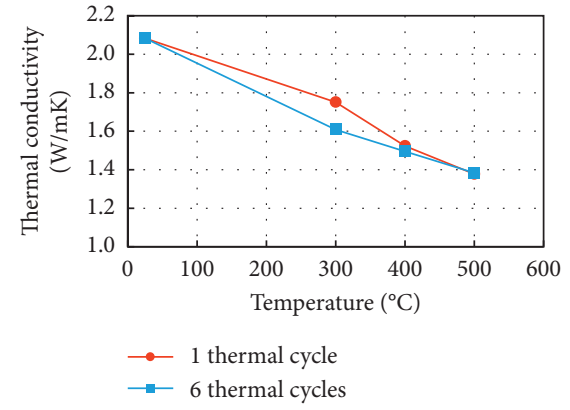

(c)

Figure 12: Comparison of thermal conductivities after one and six thermal cycles. (a) Steel fiber content $=1.0 \%$. (b) Steel fiber content $=1.5 \%$. (c) Steel fiber content $=2.0 \%$.

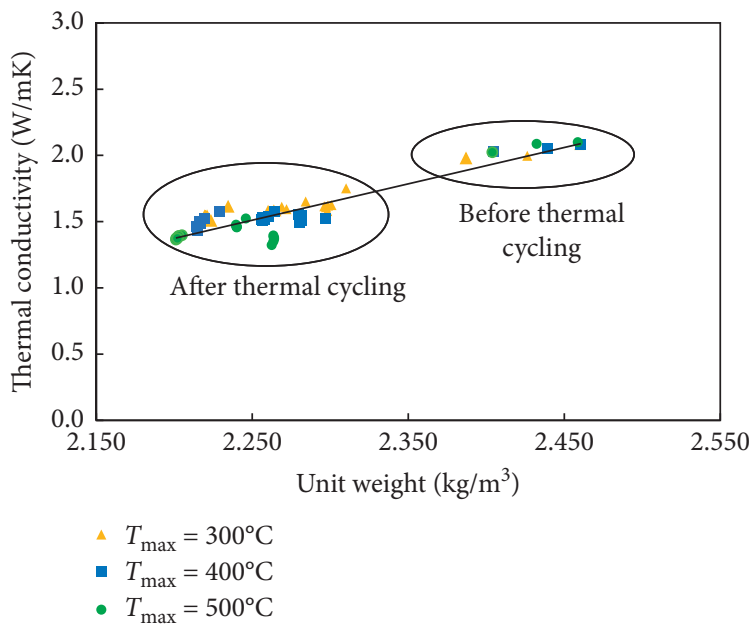

FIGURE 13: Relationship between the thermal conductivity and unit weight of the UHPC at different maximum temperatures.

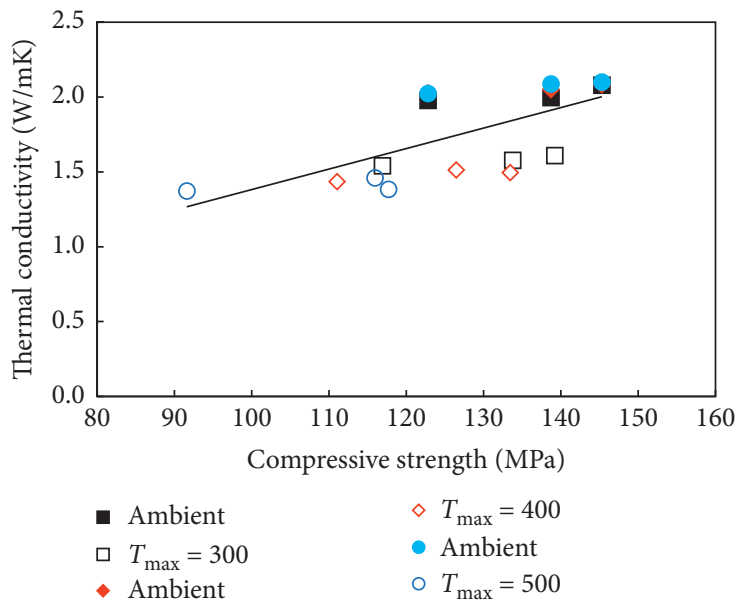

FIGURE 14: Relationship between the thermal conductivity and compressive strength of the UHPC at different maximum temperatures.

the specimens with steel fiber contents of $1.0 \%$, compared with the porosity at the initial state at ambient temperature, the porosity volume increased by $11.9,60.0$, and $60.0 \%$ after exposure to thermal cycling at maximum temperatures of 300,400 , and $500^{\circ} \mathrm{C}$, respectively. In addition, for the specimens with steel fiber contents of $1.5 \%$, compared with the porosity at the initial state at ambient temperature, the porosity volume increased by $22.9,67.9$, and $74.5 \%$ after exposure to thermal cycling at maximum temperatures of 300,400 , and $500^{\circ} \mathrm{C}$, respectively.

Compared with the porosity at the ambient temperature, the porosity at a temperature of $500^{\circ} \mathrm{C}$ increased by 60.0 , 


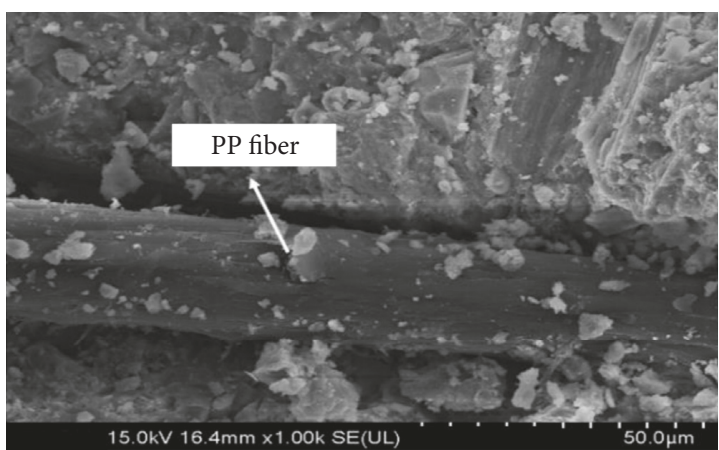

(a)

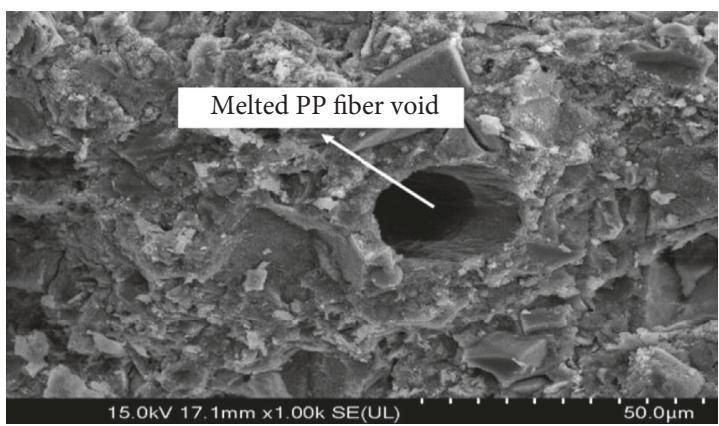

(c)

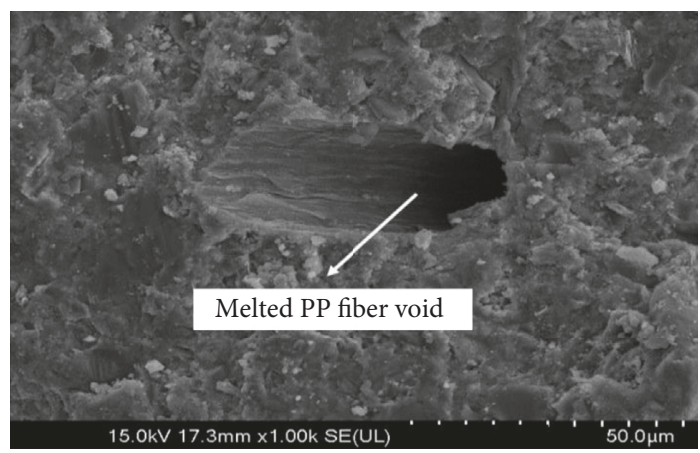

(b)

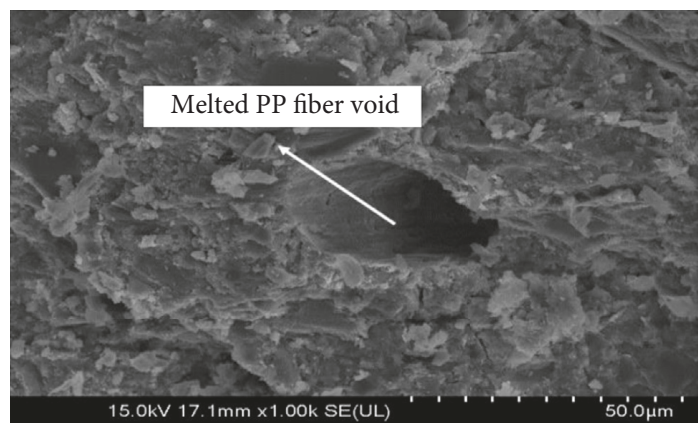

(d)

FIGURE 15: SEM analysis of the UHPC before and after thermal cycling at different temperatures. (a) SEM image before thermal cycling. (b) SEM image at $300^{\circ} \mathrm{C}$. (c) SEM image at $400^{\circ} \mathrm{C}$. (d) SEM image at $500^{\circ} \mathrm{C}$.

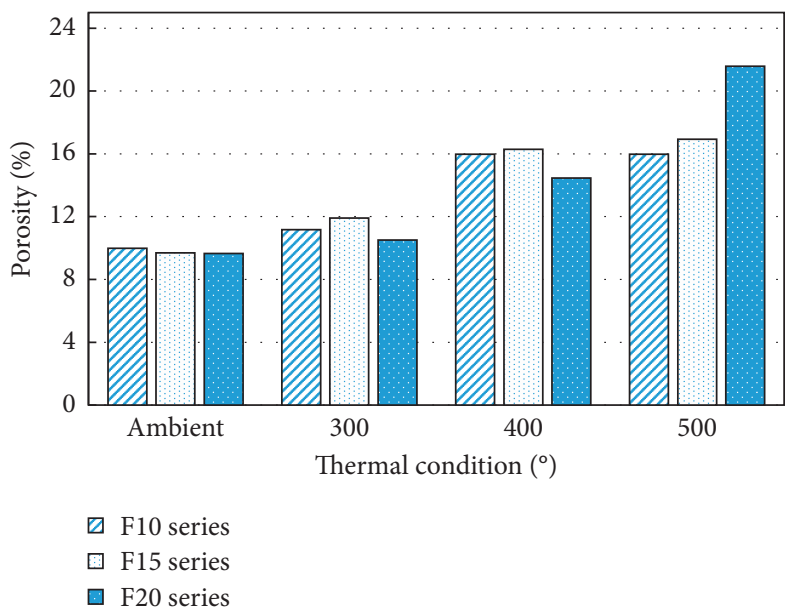

FIgURE 16: Porosity of the UHPC before and after exposure to high-temperature thermal cycling.

74.5 , and $123.4 \%$ for steel fiber contents of $1.0,1.5$, and $2.0 \%$, respectively. It resulted from incompatible thermal expansion between the concrete matrix and steel fiber. The incompatible thermal expansion weakened the interface zone between the matrix and steel fiber and so increased the porosity as steel fiber content increased.

The differential and cumulative pore size distributions of the UHPC specimens with the steel fiber content of $1.0 \%$ before and after exposure to high-temperature thermal cycling are shown in Figure 17. The mercury intrusion curves correspond to the porosity volume. The cumulative pore volume increased as the thermal cycling temperature increased. The differential and cumulative pore size distributions between approximately 0.01 and $0.1 \mu \mathrm{m}$ are remarkable compared with those for other pore sizes, which means that the pore size ranging from 0.01 to $0.1 \mu \mathrm{m}$ was most affected by thermal cycling at temperatures greater than $300^{\circ} \mathrm{C}$.

Abid et al. [20] investigated mechanical behavior and the microstructure of RPC at high temperatures of 120, 300, 500, 700 , and $900^{\circ} \mathrm{C}$. Their test results showed that for the temperatures of less than $700^{\circ} \mathrm{C}$, the pore size distribution of RPC increased in the range of $0.01 \sim 0.1 \mu \mathrm{m}$ and greater than $1 \mu \mathrm{m}$. For the range of $0.01 \sim 0.1 \mu \mathrm{m}$, the increase of pore size 


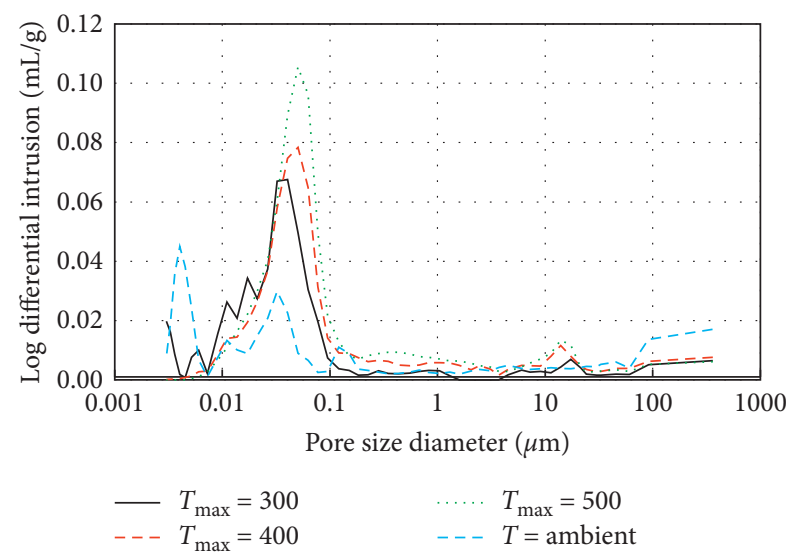

(a)

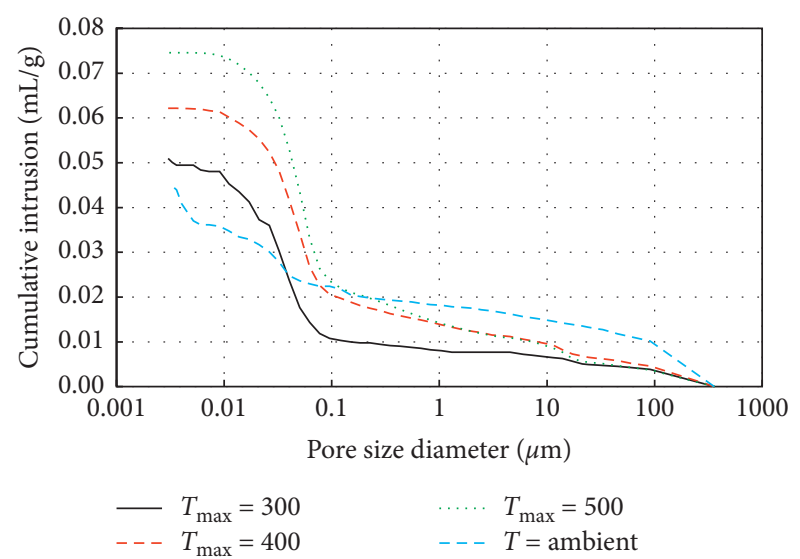

(b)

FIgURE 17: Pore size distributions of the UHPC specimens before and after exposure to thermal cycling (F10 series specimens). (a) Differential pore volume. (b) Cumulative pore volume.

distribution of UHPC in this study was overall consistent with that of RPC in the study by Abid et al., whereas for the range of greater than $1 \mu \mathrm{m}$, the pore size distribution of the UHPC was different from that of RPC.

\section{Conclusions}

This paper investigated the thermal, mechanical, and microstructural properties of UHPC with compressive strengths greater than $120 \mathrm{MPa}$. The following conclusions are drawn from the extensive experimental results:

(1) The compressive strengths of the specimens decreased as the temperature increased. When the specimens were exposed to thermal cycling at a maximum temperature of $300^{\circ} \mathrm{C}$, the decrease of the compressive strengths of the F10, F15, and F20 series mixtures ranged from 3.6 to $4.8 \%$. However, when the specimens were exposed to thermal cycling at a maximum temperature of $500^{\circ} \mathrm{C}$, the decrease of the compressive strengths of the F10, F15, and F20 series mixtures ranged more substantially from 16.4 to $25.4 \%$.

(2) The decreasing trend of the tensile strength of the UHPC was similar to that of the compressive strength. The tensile strength gradually decreased as the maximum temperature increased. In addition, the steel fiber content substantially contributed to the tensile strength of the UHPC.

(3) The unit weight decreased immediately after the first thermal cycle, but there was little change in the unit weight of the concrete after the second cycle. This finding implied that the concrete almost reached physical stability after the second thermal cycle. Moreover, the decrease in the unit weight at a maximum temperature of $500^{\circ} \mathrm{C}$ was greater than that of the unit weight at maximum temperatures of 300 and $400^{\circ} \mathrm{C}$.

(4) The decreasing trend of the thermal conductivity during the thermal cycling was similar to that of the unit weight. Moreover, test results showed that for each maximum temperature, the reduction of the thermal conductivities from one to six thermal cycles was not significant.

(5) The thermal conductivity of the UHPC decreased as the compressive strength of the UHPC decreased. When the UHPC was exposed to thermal cycling at a maximum temperature of $500^{\circ} \mathrm{C}$, the thermal conductivity of the UHPC decreased by $32.1,30.0$, and $34.1 \%$, while the compressive strength of the UHPC decreased by $25.4,16.4$, and $19.0 \%$ for steel fiber contents of $1.0,1.5$, and $2.0 \%$, respectively.

(6) SEM image analysis showed the voids from melted PP fibers when they were exposed to high-temperature thermal cycling. Moreover, the porosity volume increased as the thermal cycling temperature increased. As an example, for the specimens with steel fiber contents of $1.0 \%$, the porosity volume increased by $11.9,60.0$, and $60.0 \%$ after the UHPC was exposed to thermal cycling at maximum temperatures of 300,400 , and $500^{\circ} \mathrm{C}$, respectively.

\section{Data Availability}

The data used to support the findings of this study are available from the corresponding author upon request.

\section{Conflicts of Interest}

The authors declare that they have no conflicts of interest.

\section{Acknowledgments}

This research was supported by a grant (19CTAP-C15188901) from the Technology Advancement Research Program (TARP) funded by the Ministry of Land, Infrastructure and Transport of Korean government. 


\section{References}

[1] R. Tamme, D. Laing, and W.-D. Steinmann, "Advanced thermal energy storage technology for parabolic trough," Journal of Solar Energy Engineering, vol. 126, no. 2, pp. 794-800, 2004.

[2] J. E. Skinner, B. M. Brown, and R. P. Selvam, "Testing of high performance concrete as a thermal energy storage medium at high temperatures," in Proceedings of the ASME 2011 5th International Conference on Energy Sustainability, Washington, DC, USA, August 2011.

[3] V. A. Salomoni, C. E. Majorana, G. M. Giannuzzi et al., "Thermal storage of sensible heat using concrete modules in solar power plants," Solar Energy, vol. 103, pp. 303-315, 2014.

[4] E. E. John, W. Micah Hale, and R. P. Selvam, "Development of a high performance concrete to store thermal energy for concentrating solar power plants," in Proceedings of the ASME 2011 5th International Conference on Energy Sustainability, Washington, DC, USA, August 2011.

[5] D. Laing, W.-D. Steinmann, R. Tamme, and C. Richter, "Solid media thermal storage for parabolic trough power plants," Solar Energy, vol. 80, no. 10, pp. 1283-1289, 2006.

[6] E. John, M. Hale, and P. Selvam, "Concrete as a thermal energy storage medium for thermocline solar energy storage systems," Solar Energy, vol. 96, pp. 194-204, 2013.

[7] A. I. Fernandez, M. Martínez, M. Segarra, I. Martorell, and L. F. Cabeza, "Selection of materials with potential in sensible thermal energy storage," Solar Energy Materials and Solar Cells, vol. 94, no. 10, pp. 1723-1729, 2010.

[8] T.-C. Ling and C.-S. Poon, "Use of phase change materials for thermal energy storage in concrete: an overview," Construction and Building Materials, vol. 46, pp. 55-62, 2013.

[9] D. Laing, D. Lehmann, M. Fiß, and C. Bahl, “Test results of concrete thermal energy storage for parabolic trough power plants," Journal of Solar Energy Engineering, vol. 131, no. 4, Article ID 0410071, 2009.

[10] D. Laing, C. Bahl, T. Bauer, M. Fiss, N. Breidenbach, and M. Hempel, "High-temperature solid-media thermal energy storage for solar thermal power plants," Proceedings of the IEEE, vol. 100, no. 2, pp. 516-524, 2012.

[11] H. Yuan, Y. Shi, Z. Xu, C. Lu, Y. Ni, and X. Lan, "Influence of nano- $\mathrm{ZrO}_{2}$ on the mechanical and thermal properties of high temperature cementitious thermal energy storage materials," Construction and Building Materials, vol. 48, pp. 6-10, 2013.

[12] H. Yuan, Y. Shi, Z. Xu, C. Lu, Y. Ni, and X. Lan, "Effect of nano-MgO on thermal and mechanical properties of aluminate cement composite thermal energy storage materials," Ceramics International, vol. 40, no. 3, pp. 4811-4817, 2014.

[13] B. A. Graybeal, "Material property characterization of ultrahigh performance concrete," Report No. FHWA-HRT-06103, FHWA, U.S. Department of Transportation, McLean, VA, USA, 2006.

[14] T. Leutbecher and E. Fehling, "Tensile behavior of ultra-highperformance concrete reinforced with reinforcing bars and fibers: minimizing fiber content," ACI Structural Journal, vol. 109, no. 2, pp. 253-263, 2012.

[15] I.-H. Yang, C. Joh, and B.-S. Kim, "Flexural response predictions for ultra-high-performance fibre-reinforced concrete beams," Magazine of Concrete Research, vol. 64, no. 2, pp. 113-127, 2012.

[16] A. Abrishambaf, M. Pimentel, and S. Nunes, "Influence of fibre orientation on the tensile behaviour of ultra-high performance fibre reinforced cementitious composites," Cement and Concrete Research, vol. 97, pp. 28-40, 2017.
[17] K.-C. Kim, I.-H. Yang, and C. Joh, "Effects of single and hybrid steel fiber lengths and fiber contents on the mechanical properties of high-strength fiber-reinforced concrete," Advances in Civil Engineering, vol. 2018, Article ID 7826156, 14 pages, 2018.

[18] J.-H. Lee, Y.-S. Sohn, and S.-H. Lee, "Fire resistance of hybrid fibre-reinforced, ultra-high-strength concrete columns with compressive strength from 120 to $200 \mathrm{MPa}$," Magazine of Concrete Research, vol. 64, no. 6, pp. 539-550, 2012.

[19] A. Iravani and S. Anders, "Time dependent mass loss of UHPC after single and cyclic thermal exposure," in Proceedings of HiperMat, Kassel, Germany, 2016.

[20] M. Abid, X. Hou, W. Zheng, and R. R. Hussain, "Effects of fibers on high-temperature mechanical behavior and microstructures of reactive powder concrete," Materials, vol. 12, no. 2, pp. 1-30, 2019.

[21] G.-F. Peng, W.-W. Yang, J. Zhao, Y.-F. Liu, S.-H. Bian, and L.-H. Zhao, "Explosive spalling and residual mechanical properties of fiber-toughened high-performance concrete subjected to high temperatures," Cement and Concrete Research, vol. 36, no. 4, pp. 723-727, 2006.

[22] S. Aydin, H. Yazıcı, and B. Baradan, "High temperature resistance of normal strength and autoclaved high strength mortars incorporated polypropylene and steel fibers," Construction and Building Materials, vol. 22, no. 4, pp. 504-512, 2008.

[23] W.-C. Wang, "Compressive strength and thermal conductivity of concrete with nanoclay under various high-temperatures," Construction and Building Materials, vol. 147, pp. 305-311, 2017.

[24] M. Abid, X. Hou, W. Zheng, and R. R. Hussain, "High temperature and residual properties of reactive powder concrete-a review," Construction and Building Materials, vol. 147, pp. 339-351, 2017.

[25] X. Li, Y. Bao, L. Wu et al., "Thermal and mechanical properties of high-performance fiber-reinforced cementitious composites after exposure to high temperatures," Construction and Building Materials, vol. 157, pp. 829-838, 2017.

[26] T. Log and S. E. Gustafsson, "Transient plane source (TPS) technique for measuring thermal transport properties of building materials," Fire and Materials, vol. 19, no. 1, pp. 43-49, 1995.

[27] D. Bentz, M. Peltz, A. Durán-Herrera, P. Valdez, and C. Juárez, "Thermal properties of high-volume fly ash mortars and concretes," Journal of Building Physics, vol. 34, no. 3, pp. 263-275, 2011. 


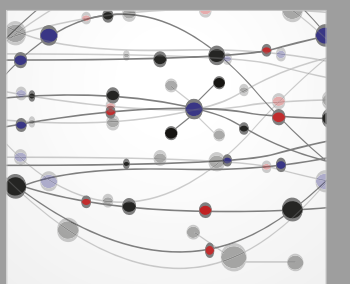

The Scientific World Journal
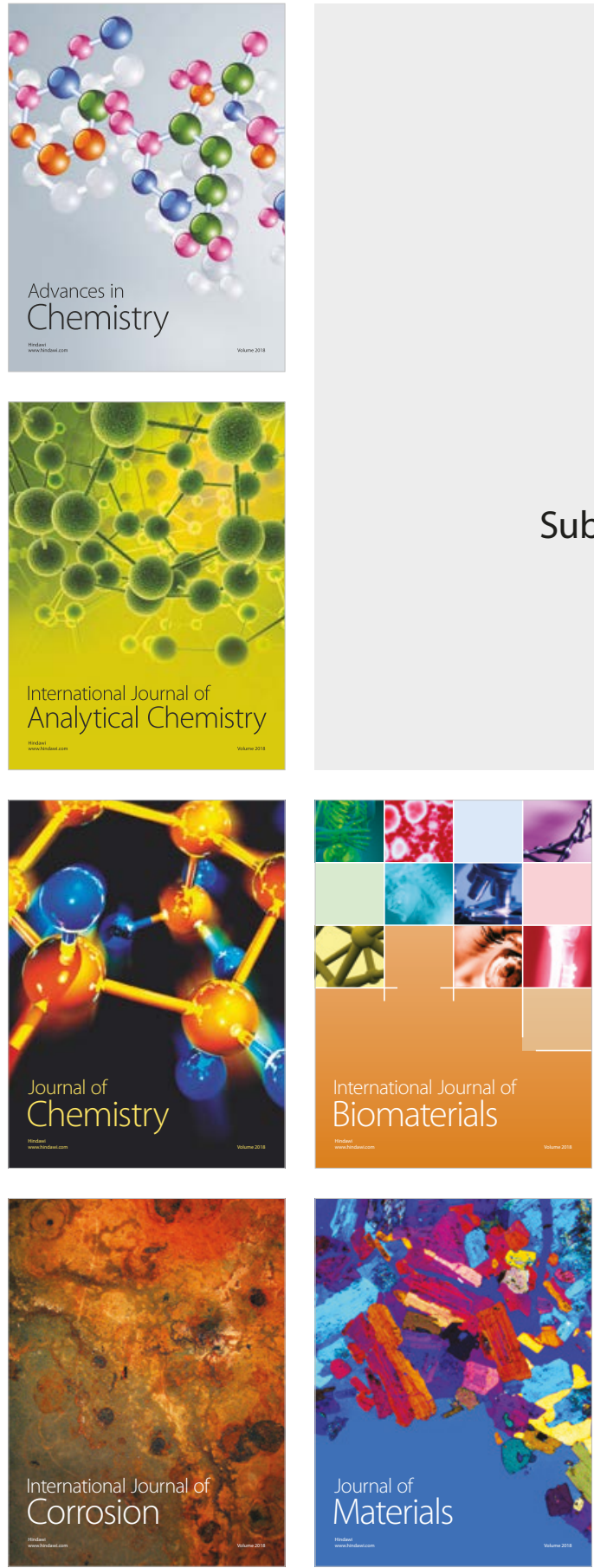

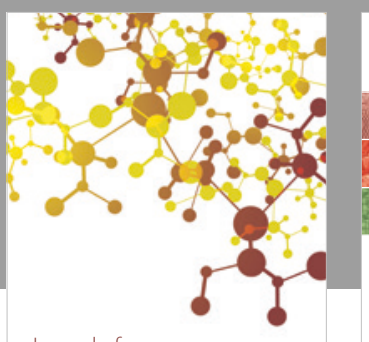

Journal of

Applied Chemistry
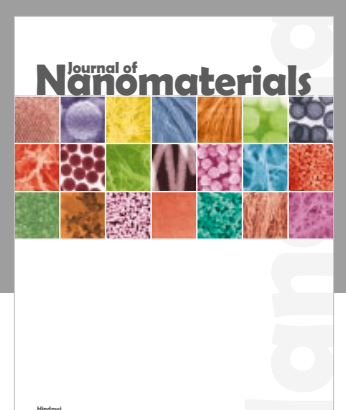

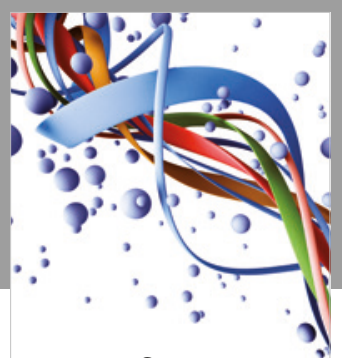

Scientifica

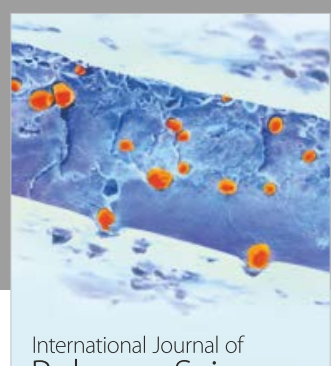

Polymer Science

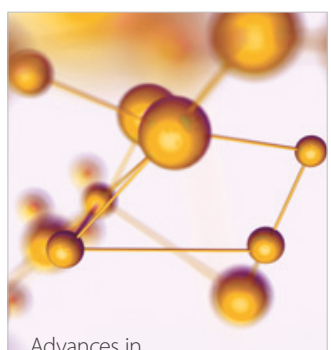

Physical Chemistry
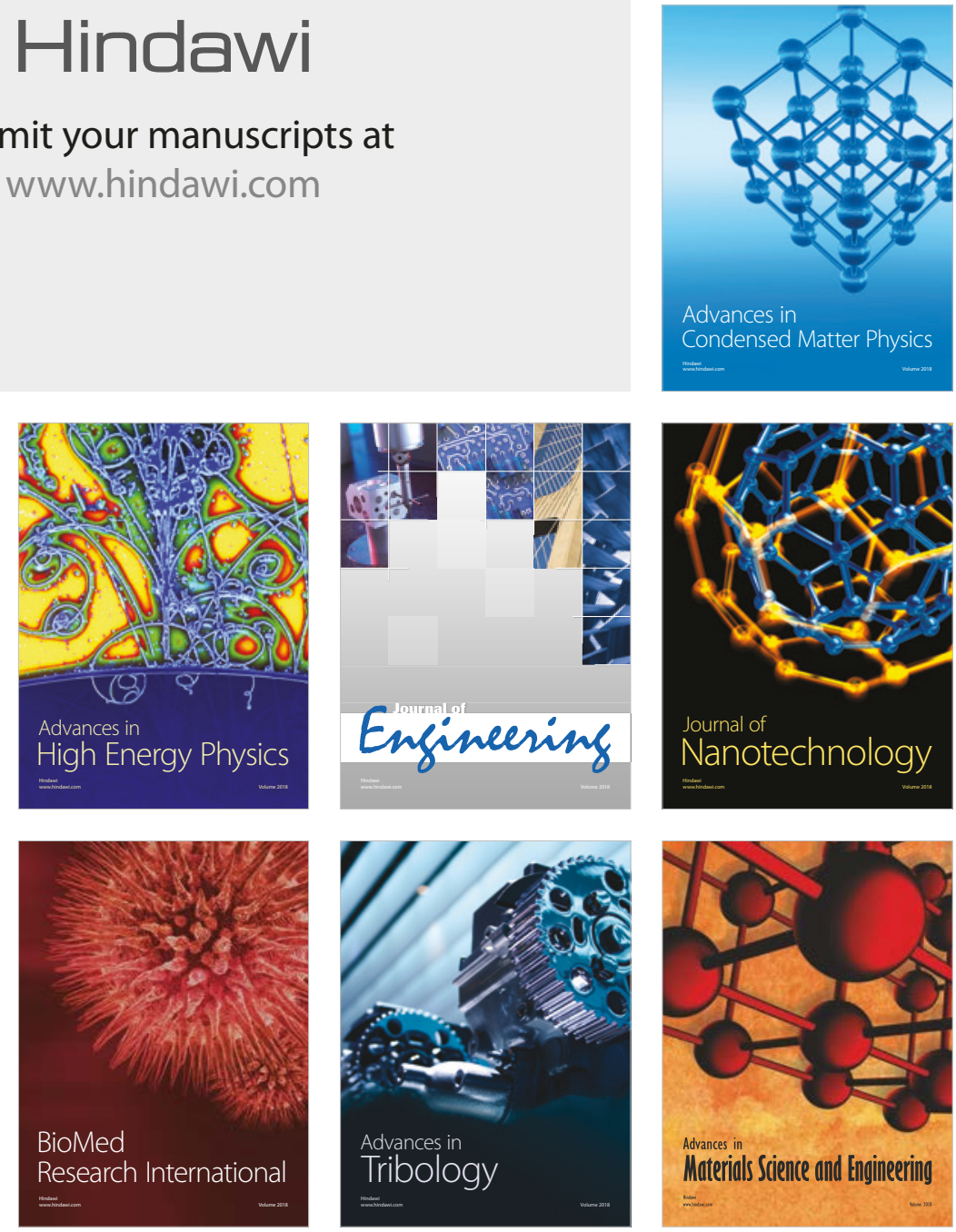